\title{
TEACHING LIFE SCIENCES USING SECOND LANGUAGE: HOW DO TEACHERS COPE?
}

\author{
Amos Motloung, \& Lydia Mavuru \\ Department of Science and Technology Education, University of Johannesburg (South Africa)
}

\begin{abstract}
Language plays a pivotal role in science teaching and learning as it serves as both the medium through which the teachers and learners think and also communicate in the classrooms. Science and Life sciences in particular comprises of a unique scientific language register with a lot of technical words and terms borrowed from other languages other than English. Previous researchers acknowledged the difficulty teachers face when teaching science in a language different from their own and that of the learners. Consequently, the current study explored the various ways in which English-second-language Life Sciences teachers taught Life Sciences in order to mitigate language difficulties for themselves and those of their learners. The study was guided by the research question: how does English as a second language influence teacher practices when teaching Life Sciences to grade 12 learners? Using a qualitative research design, six Life Sciences teachers with various levels of teaching experience, two novices, two relatively experienced and two very experienced teachers, were purposefully selected from six different schools. The assumption was that teachers at various levels of experience may have different experiences of teaching the subject in a second language. Each teacher was observed once whilst teaching the same topic to grade 11 Life Sciences learners to establish their teaching practices. Incidences of learner engagement with the content, teacher-learner and learner-learner interactions were captured and scored using the Reformed Teaching Observation Protocol rubric. Lesson observations were suitable for data collection as they allowed the researcher to examine even non-elicited behaviour as it happened. The findings indicated that language difficulties were prevalent and affected both teachers and learners in engaging with the concepts at hand. For instance, most of the teachers whether experienced or not, struggled to explain and elaborate vital Life Sciences concepts in a comprehensible manner due to lack of proficiency in the language of instruction. The teachers mostly utilised code-switching as it enabled them to explain and elaborate scientific terms and processes in both English and their home languages. Because learners were allowed to express themselves in their home languages, the level of interaction also increased. In addition, teachers used transliteration and demonstrations as teaching strategies that also reduced the challenges of using English as a medium of instruction. The study informs both pre-service and in-service teacher development programmes.
\end{abstract}

Keywords: Life sciences, English-second-language-speakers, teacher practices, code switching.

\section{Introduction}

Language plays a very important role in both teaching and learning. Through language, communication can occur which allows for the transmission of knowledge. However, in South African township schools it is difficult to foster educational goals due to the language constraints that are faced by English-second-language (ESL) speakers. Hence, it is imperative that ESL teachers deploy strategies that allow them to cope with the language demands in such schools. In addition, Life Sciences is characterised by a variety of scientific terms, which are unfamiliar to both English-first-language speakers (EFL) and ESL speakers (Ferreira, 2011; Oyoo, 2004). ESL learners experience difficulties in acquiring the main concepts or themes addressed in science classes and therefore it is important that language use in Life Sciences classrooms is addressed (Gudula, 2017; Feez \& Quinn, 2017; Oyoo, 2004). The reason for such difficulties is that the teaching of sciences involves not only teaching the content but also teaching the scientific language.

\section{Literature review}

The nature of this study was to establish teachers' experiences in teaching Life Sciences in English, a second if not a third language to most of the township teachers. A large body of research on language issues in science learning reveals that ESL teachers are at the centre of all issues arising from 
teaching sciences in the second language (Feez \& Quinn, 2017; Gudula, 2017; Prinsloo, Rodgers, \& Harvey, 2018). One of the most prominent issues that arises from these studies is the acquisition of scientific concepts by learners. Most learners from township schools are ESL speakers and therefore find it difficult to comprehend some of the scientific concepts because they are foreign to them (Prinsloo et al., 2018). Hence, it is vital to explore the strategies that Life Sciences teachers employ to combat such issues.

Setati (2002) emphasised the significance of teacher language proficiency in science classes. While most ESL teachers are proficient in using English whilst teaching, they still prefer to clarify some difficult science concepts using their home languages. This highlights the need for township teachers to be proficient in more than one language and it also highlights the importance of code-switching when explaining science concepts (Feez \& Quinn, 2017). However, code switching tends to be problematic because some science concepts are watered down in the process, and therefore learners fail to engage meaningfully with such concepts. In addition, studies by Ferreira (2011), Gudula (2017) and Oyoo (2004) posited the need for science teachers to effectively use scientific language in portraying scientific themes. Therefore, it is vital to explore how teachers cope in teaching Life Sciences using their second language. The usage of code-switching in township science classes can be regadered as a way in which ESL teachers cope with the language demands presented by Life Sciences.

\subsection{Code-switching}

In South African classrooms, code-switching is one of the widely applied strategies to give meaning to science concepts (Ferreira, 2011). Code-switching involves teaching the same concept in English and then in another language (Oyoo, 2004). This implies that teachers should be multilingual and fluent in more than one language (Setati, 2002). Furthermore, Mthiyane (2016) asserted that using the learners' home language has the potential to convey powerful meanings to abstract science concepts. In addition, Oyoo (2017) emphasised that code-switching serves as a bridge between the learners' home language though it tends to water down some of the fundamental science concepts. Because code-switching is against the South African language policy, some teachers are reluctant to engage learners in their home languages (Ferreira, 2011). Oyoo (2017) confirmed that the language teachers use in a science class is constrained by the requirement of the content to be taught and learnt, thus teachers may feel reluctant to engage learners in their home language.

Township schools are generally multicultural schools, and since learners in these schools are mostly ESL speakers, Life Sciences teachers resort to code switching as a way of fostering scientific concepts that are mostly problematic to learners (Alhamami, 2019; Feez \& Quinn, 2017; Mthiyane, 2016; Prinsloo et al., 2018; Probyn, 2016). Studies reveal that code-switching is the preferred method applied by Life Sciences teachers and they also show that code-switching is used to facilitate communication and interaction between teachers and learners. However, some studies show that, though regarded a fruitful process, code-switching can also contribute to science language problems that occur in the classrooms (Boateng, 2019; Oyoo, 2017). Such problems can include the inability of teachers to speak all the different languages that are represented in that particular class. Learners in a Life Sciences class have different linguistic backgrounds and, because of this, teachers may only explain some concepts to learners who speak the same language they speak, and thus disadvantage those who speak a different language. Since code-switching involves moving from one language to the next (Prinsloo et al, 2018), it is unlikely that teachers are proficient in all 11 official South African languages. Hence, it can be difficult to accommodate all learners from different cultural backgrounds.

\section{Methodology}

\subsection{Research design}

This study followed a qualitative approach in determining how teachers teach Life Sciences using their second language. Creswell (2011) pointed out that a qualitative research design allows for the investigation of the phenomenon within its real life context. The design was suitable for this study because data was collected from Life Sciences teachers in real classrooms in township schools. Similarly, a qualitative approach makes it possible to study "things in their natural settings, attempting to make sense of or interpret phenomena in terms of the meanings people bring to them" (Denzin \& Lincoln, 2005, p. 3).

\subsection{Sampling}

Purposive and convenience sampling was used (Patton, 1990) to select six teachers who were ESL speakers from six township schools for the study. According to Patton (1990), purposive sampling allows for the selection of information-rich cases, where the researcher can obtain a great deal of data regarding the matter at hand, and in this case, how teachers teach Life Sciences using English. 
Furthermore, Etikan, Musa and Alkassim (2016) maintained that purposive sampling allows for the selection of participants that provide a distinctive and information-rich value to the study. The Life Sciences teachers had different teaching experiences: two novice teachers (N), Zanele and Mulalo, (zero to two years); two relatively experienced teachers (RE), Koali and Sizwe, (three to five years); and two very experienced (VE) teachers, Phale and Shilubane, (six years and above). The assumption was that teachers at various levels of experience may have different experiences in teaching Life Sciences using English as their second language. Denzin and Lincoln (2005) claimed that those involved in a qualitative research should be directly linked or affected by the problem researched, hence the involvement of these participants.

\subsection{Data collection}

Data collection involved observing each of the six teachers once to gain insights into how they teach grade 11 Life Sciences using English, which is their second language. A revised Reformed Teaching Observation Protocol (RTOP) was used to capture the level of each teacher and their learners' involvement during the lessons (Sawada, Piburn, Falconer, Turley, Benford, Bloom, \& Judson, 2000). See Table 1 for the categories in RTOP. Incidents of learner engagement with the content, teacher-learner and learner-learner interactions were captured and scored using the RTOP rubric. The lessons were video-recorded with permission from the participants. Mills (2011) pointed out that observations allow the researcher to examine non-elicited behaviour as it happens. Hence, this was significant in obtaining a holistic experience on how language is used in the classroom. In the same vein, Creswell (2011) inferred that, observations provide a more complete description of the phenomenon that would be impossible by analysing interview documents.

\subsection{Data analysis}

The lesson observations showing evidence of teacher and learners' involvement during the lessons were coded and analysed using an interpretive approach (Fontana \& Frey, 2003). The information was broken down into smaller units and each response was thoroughly interpreted, explained and analysed to make meaningful cohesion between participants' classroom observations (Cohen, Manion, $\&$ Morrison, 2000). Trends between the participants' observations were examined for any emerging themes. A correlation between themes and the research question was formulated and interpreted.

\subsection{Reliability, validity and transferability}

To ensure validity and reliability of the data from observations, the first and second author read the RTOP scores repeatedly and reviewed any emerging patterns and trends. The interpretations were further validated by checking with the participant teachers on any emerging themes.

\section{Findings}

In determining answers to the research question which sought to explore how teachers teach 1 Life Sciences in their second language, lesson observations were done. Each of the six teachers was observed once and scored using the RTOP scoring rubric. Table 1 shows teachers' scores for each of the RTOP categories.

Table 1. Teachers' scores in the different RTOP categories.

\begin{tabular}{|l|c|c|c|c|c|c|}
\hline & \multicolumn{6}{|c|}{ Teachers' scores with RTOP categories (out of 100) } \\
\cline { 2 - 7 } $\begin{array}{l}\text { Teachers' } \\
\text { pseudonyms }\end{array}$ & $\begin{array}{c}\text { Lesson design } \\
\text { and } \\
\text { implementation }\end{array}$ & $\begin{array}{l}\text { Propositional } \\
\text { knowledge }\end{array}$ & $\begin{array}{l}\text { Procedural } \\
\text { knowledge }\end{array}$ & $\begin{array}{l}\text { Communicative } \\
\text { interactions }\end{array}$ & $\begin{array}{c}\text { Learner- } \\
\text { Teacher } \\
\text { relationships }\end{array}$ & $\begin{array}{c}\text { Average } \\
\text { scores }\end{array}$ \\
\hline Phale & 60 & 65 & 35 & 55 & 70 & 57 \\
\hline Shilubane & 65 & 60 & 45 & 80 & 75 & 65 \\
\hline Koali & 80 & 85 & 55 & 90 & 80 & 78 \\
\hline Zanele & 60 & 70 & 50 & 60 & 65 & 61 \\
\hline Mulalo & 50 & 65 & 55 & 50 & 55 & 55 \\
\hline Sizwe & 70 & 65 & 60 & 65 & 65 & 65 \\
\hline Average scores & 64 & 71 & 50 & 67 & 68 & 64 \\
\hline
\end{tabular}

The findings revealed that though the participants taught in similar contexts, they did not experience the same. This is prominent in the variances between their RTOP scores. It is notable that teachers struggled with the language demands in the Life Sciences classes at all levels of experiences. Very experienced teachers and novice teachers struggled in the same way to cope with the scientific language demands. Hence some participants resorted to code-switching as a way of ensuring that science concepts are grasped by the learners. 
The total scores of the six teachers show a big difference and therefore share light on the way in which these teachers experienced the teaching of Life Sciences using their second language. For instance, Phale (VE) managed to get an average score of $57 \%$, which is very low. In this case, it shows that experience does not necessarily mean that a teacher will be effective in the classroom. For example, throughout the lesson, Phale only focused on delivering the content, and although he would code switch every now and then, it was not effective because the code-switching occurred in Sesotho. Since some of the learners were not Sotho speaking, there was a breakdown in communication. Some learners would make the following remarks: "Asisizwa isiSotho" which means they do not understand the Sesotho language. This illustrates that language plays a vital role in the teaching and learning of science concepts. It also highlights the need for township teachers to be proficient in more than one language. Shilubane (VE) had a fair average of $65 \%$, and although he had 16 years of experience, he did not score the highest. However, it is notable that during his lesson the language of instruction was mostly used. There was some code-switching that occurred effectively, because the learners were able to interact and engage meaningfully in the lesson.

Koali (RE) had the highest average score of $78 \%$ compared to other participants. One aspect that typified Koali's class was the teacher-learner interaction. This resulted from the usage of the Sesotho and IsiZulu language throughout the lesson. Though most of the lesson took place in the teacher's and learners' home language(s), it was noted that the level of engagement was high, and learners were able to participate effectively in the lesson, since they were not confined to using English. Mavuru and Ramnarain (2019) described the importance of familiarising science concepts to the learners so that they easily relate to them. This is significant in ensuring conceptual change.

Zanele (N) managed to obtain an average score of $61 \%$, she was one of the least experienced teachers with only two years of teaching experience. When teaching the respiratory diseases, she would play some videos that kept learners engaged in the lesson. However, because she mostly taught in English and hardly code switched, it was notable that some learners were disoriented in the lesson.

Mulalo (N) had the lowest average of 55\%. He was in his second year of teaching; hence some of the difficulties that arose in his classroom were directly linked to his inexperience. For instance, during the lesson he mostly used English, which would account for the lack of engagement of learners. Furthermore, the mispronunciation of some terms showed that he also lacks proficiency in the scientific language, which would explain the lower score. On the contrary, Sizwe (RE) managed to obtain 65\%, which was the same total score obtained by one of the most experienced teachers, Shilubane. Sizwe's scores on the RTOP items were mostly consistent, and during the lesson observation, it was established that he showed a great level of proficiency in the language of instruction. This impacted positively on the learners as the level of interaction in the classroom was fairly normal.

\subsection{Discussion of findings from lesson observations}

The findings indicate a very important aspect, that is, language difficulties in science classes are prevalent and ESL speakers struggle to cope with the language demands in these classes. This can be seen through the low scores that both experienced and inexperienced teachers obtained. This confirms Oyoo's (2017) findings, that ESL teachers struggle to meet the demands of not only the language of instruction but the scientific language too. The low average scores of experienced teachers like Phale and Shilubane, serve as evidence to show that language difficulties are experienced by all. Ferreira (2011) highlighted the need for ESL teachers to regularly code-switch when explaining some of the difficult concepts in Life Sciences. The findings in this study revealed that teachers used code-switching more frequently as a way of coping with the difficult language demands in Life Sciences Life Sciences classes. In this case, it is important to note that code-switching was not used only as a teaching method to try simplify difficult science concepts, rather it was also used as a way in which teachers tried to cope with the difficult scientific register. This affirms Probyn (2016), that code-switching for ESL speakers is not only a teaching aid, but rather a coping mechanism for both the language of instruction and the scientific language.

\section{Conclusion and implications}

This study explored how teachers teach Life Sciences using their second language and the means in which they use to cope with the language demands. In order to cope with the language difficulties, teachers used code switching. Previous studies have also advocated for the use of a language that is familiar to both teachers and learners to combat the constraints that are often paused by the use of the second language in science classes. The emphasis in this case, is that teachers' use of language in science classes influences their teaching, which eventually will affect learners' acquisition of scientific concepts. For instance, the RTOP scores obtained by teachers, especially with regard to teacher-learner interactions and communicative practices, showed that the teachers who scored the highest often practised 
code-switching. And in interpreting why such findings were obtained, factors such as proficiency in both the home language and English were raised, as some teachers, especially those that were not proficient in the learners' home languages, struggled to convey some of the vital concepts to learners. The researchers believe that Life Sciences is strongly affected by the language policy and, therefore, Life Sciences teachers in township schools should be aware of the difficulties and challenges that are faced by both teachers and learners.

\section{References}

Alhamami, A. (2019). Language of instructional science programs: science university students' voices. Journal Pendidikan IPA Indonesia, 8(10), 110-118.

Boateng, P. (2019). Managing transitions from mother tongue instruction to English as the medium of instruction. United Kingdom: UK Department for International Development and other Government departments.

Cohen, L., Manion, L., \& Morrison, K. (2000). Research methods in education. London: Routledge Falmer.

Creswell, J. W. (2011). Educational research: Planning, conducting, and evaluating quantitative and qualitative approaches to research $\left(4^{\text {th }}\right.$ ed). Upper Saddle River: Person Education.

Denzin, N. K., \& Lincoln, Y. S. (2005). The Sage handbook of qualitative research. Thousand Oaks, CA: Sage.

Etikan I., Musa S. A., \& Alkassim, R. S. (2016). Comparison of convenience sampling and purposive sampling. American Journal of Theoretical and Applied Statistic, 5(1), 1-4. doi: $10.11648 /$ j.ajtas.20160501.11

Feez, S., \& Quinn, F. (2017). Teaching the distinctive language of science: an integrated and scaffolded approach for pre-service teachers. Teaching and Teacher Education, 65, 192-204. doi: https:doi.org/10.1016/j.tate.2017.03.019

Ferreira, J. G. (2011). Teaching life sciences to English second language learners: what do teachers do? South African Journal of Education, 31, 102-113. doi: 10.15700/saje.31n1a409

Fontana, A., \& Frey, J. H. (2003). The interview: from structured questions to negotiated text. In N. Denzin and Y. S. Lincoln (Eds). Collecting and interpreting qualitative materials, 2nd Edition. (pp. 61-106). Thousand Oaks, CA: Sage.

Gudula, Z. (2017). The influence of language on the teaching and learning of natural sciences in Grade 7. MEd dissertation. Bellville, South Africa: University of Western Cape.

Mavuru, L., \& Ramnarain, U. (2019). Language affordances and pedagogical challenges in multilingual grade 9 natural sciences classrooms in South Africa. International Journal of Science Education, doi: 10.1080/09500693.2019.1655177

Mills, G. E. (2011). Action research: A guide for the teacher researcher (4th ed.). Boston, MA: Pearson.

Msimanga, A., \& Lelliot, A. (2013). Talking science in multilingual contexts in South Africa: Possibilities and challenges for engagement in learners' home languages in high school classrooms. International Journal of Science Education, 10(14), 1-25. doi: 10.1080/09500693.2013.851427

Mthiyane, N. (2016). Pre-service teachers' beliefs and experiences surrounding the use of language in science classrooms: A South African case study. Nordic Journal of African Studies, 25(2), $111-129$.

Oyoo, S. O. (2004). Effective teaching of science: the impact of physics teachers' classroom language. PhD thesis. Victoria, Australia: Monash University.

Oyoo, S. O. (2017). Learner outcomes in science in South Africa: role of the nature of learner difficulties with the language for learning and teaching science. Journal of Science Education, 47, 783-804. doi:10.1007/s11165-016-9528-8

Patton, M. Q. (1990). Qualitative evaluation and research methods. 2nd ed. Newbury Park, CA: Sage.

Prinsloo, C. H., Rodgers, S. C., \& Harvey, J. C. (2018). The impact of language factors on learner achievement in science. South African Journal of Education, 38(1), 1-12. doi: $10.15700 /$ sajev38n1a1431

Probyn, G. (2016). Language and opportunity to learn science in bilingual classroom in the Eastern Cape. Cape Town: University of Cape Town.

Sawada, D., Piburn, M. D., Falconer, R., Turley, J., Benford, R., Bloom, I., \& Judson, E. (2000). Reformed teaching observation protocol (RTOP) training guide. Phoenix, AZ: Arizona Board of Regents.

Setati, M. (2002). Researching mathematics education and language in multilingual South Africa. The Mathematics Educator, 12(2), 6-20. 